\title{
Contribuição ao estudo farmacognóstico da Piper ovatum Vahl
}

SILVA, D.R. ${ }^{1 ;}$ BRENZAN, M.A. ${ }^{\prime}$; ALBIERO, A.L.M. ${ }^{2}$, CORTEZ, L.E.R. ${ }^{3}$, CORTEZ, D.A.G. ${ }^{2 *}$ ${ }^{1}$ Programa de Pós-Graduação em Ciências Farmacêuticas, Universidade Estadual de Maringá, Av. Colombo 5790, 87020-900 Maringá, Paraná, Brasil. '2Departamento de Farmácia, Universidade Estadual de Maringá, Av. Colombo 5790, 87020-900 Maringá, Paraná, Brasil. ${ }^{3}$ Departamento de Farmácia, Centro de Ensino Superior de Maringá, Av. Guedner, 1610, 87050-390 Maringá, Paraná, Brasil. *dagcortez@uem.br

\begin{abstract}
RESUMO: O presente estudo descreve as características morfo-anatômicas dos órgãos vegetativos e do pó da Piper ovatum Vahl de modo que os dados obtidos possam ser utilizados como referência em análises de controle de qualidade de amostras de fármacos, a fim de verificar sua autenticidade. As raízes, caules, pecíolos e folhas foram fixadas, seccionadas à mão livre e coradas, as secções transversais e paradérmicas foram analisadas por microscopia óptica e a superfície do limbo foi observada, também, por microscopia eletrônica de varredura (MEV). Os órgãos vegetativos da $P$. ovatum apresentam morfologia e anatomia similar às outras espécies de Piper. No entanto, não foram observadas inclusões celulares nas folhas de $P$. ovatum. Análises por MEV mostraram a presença de tricomas glandulares constituídos de pedúnculo unicelular e porção secretora globóide igualmente unicelular recoberto por cutícula, na epiderme abaxial das folhas. Também foi observada a presença de uma cutícula espessa e que origina crostas no limite entre uma célula e outra, em ambas as superfícies foliares. No mesófilo foi observada a presença de idioblastos oleíferos característica marcante de outras espécies de Piperaceae. Além disso, na microscopia do pó foram observados hipoderme e idioblastos oleíferos em fragmentos do limbo, fragmentos de fibras esclerenquimáticas do caule, além de células esclerosas isoladas ou em grupos no pecíolo. O perfil cromatográfico do extrato hidroetanólico das folhas de $P$. ovatum foi obtido por cromatografia líquida de alta eficiência (CLAE). Nas análises por CLAE foram identificados como substâncias majoritárias do extrato as amidas piperovatina e piperlonguminina nos tempos de retenção de 10,25 e 10,81 min., respectivamente.
\end{abstract}

Palavras-chave: Piper ovatum, farmacobotânica, piperovatina, piperlonguminina, perfil cromatográfico.

ABSTRACT: Contribution to the pharmacognostic study of Piper ovatum Vahl. The present study describes the morphological and anatomical characteristics of vegetative organs and powder of the Piper ovatum Vahl, in order to use the obtained data as reference in the quality control tests of pharmaceutical samples, investigating their authenticity. The roots, stems, petioles and leaves were fixed, freehand sectioned and stained according to usual microtechniques. The transverse and paradermal sections were analyzed by optical microscopy and the leaf surface was also observed by scanning electron microscopy (SEM). The vegetative organs of the P. ovatum show morphology and anatomy similar to other species of Piper. However, cellular inclusions were not observed in the $P$. ovatum leaves. The SEM analysis showed the presence of glandular trichomes consisting of a unicellular stalk and globular secretory portion covered by cuticle on the abaxial surface of the leaves. The SEM also had shown one thick cuticle forming crusts in the limit of the epidermal cells, on both leaf surfaces. In the mesophyll, we observed oil idioblasts, which are typical features of other species of Piperaceae. Moreover, in the powder of the $P$. ovatum we observed hypodermis and oil idioblasts in leaf fragments, fragments of sclerenchyma fibers from the stem and isolated sclereids or in petiole groups. The chromatographic profile of the hydroethanolic extract of the $P$. ovatum leaves was obtained by high performance liquid chromatography (HPLC). In this analysis, we identified the amides piperovatine and piperlonguminine in the retention times of 10.25 and $10.81 \mathrm{~min}$., respectively, as majority compounds present in the extract.

Key words: Piper ovatum, pharmacobotany, piperovatine, piperlonguminine, chromatographic profile. 


\section{INTRODUÇÃO}

Segundo Souza \& Lorenzi (2005) a família Piperaceae apresenta dez gêneros e aproximadamente 2000 espécies, das quais cerca de 500 espécies são muito comuns nas florestas brasileiras, particularmente na Mata Atlântica, onde predominam as espécies dos gêneros Piper e Peperomia.

As espécies de Pipersão pequenos arbustos ou árvores sublenhosas que se caracterizam pela presença de nós foliares geniculados, folhas de base assimétrica e pela presença de espigas de flores sésseis opostas as folhas (Souza \& Lorenzi, 2005).

Aspectos anatômicos da família Piperaceae foram estudados por Solereder (1908), Metcalfe \& Chalck (1972) além de outros autores. Esses estudos demonstraram que algumas espécies de Piper tais como: P. betle, P. execelsum, P. nigrum, P. jaborandi, $P$. methysticum e $P$. fluminense apresentam células oleíferas nas folhas e em outros órgãos. Mais recentemente Albiero e colaboradores (Albiero et al., 2005a; 2006) estudando Piper crassinervium e Piper hispidum constataram a presença de idioblastos oleíferos nos órgãos vegetativos e reprodutivos daquelas plantas.

Estudos demonstraram que as espécies de Piper possuem atividade antibacteriana, antifúngica e antiprotozoários, estando essas atividades relacionadas com algumas substâncias, tais como: amidas, alcalóides, lignanas, neolignanas, terpenos e derivados do ácido benzóico (Zacchino et al., 1997; Park et al., 2002; López et al., 2002; Martins et al., 2003; Pessini et al., 2003).

Grayer \& Harborne (1994) demonstraram a atividade antifúngica em Penicillium oxalicum da cromona, 2-metil-8-hidróxi-2,2-dimetil-2H-cromona6-carboxilato isolada de $P$. aduncum.

Salazar et al. (2005) verificaram a atividade antifúngica de cromonas presentes em folhas e caules de Peperomia villipetiola, o ácido 5-metanol-7-metóxi-2,2-dimetil-2H-1-cromona-6carboxílico apresentou atividade para Cladosporium cladosporioides na concentração inibitória mínima (CIM) de $100 \mu \mathrm{g} / \mathrm{ml}$, e a metil 5-acetoximetanol7-hidróxi-2,2-dimetil-2H-1-cromona-6-carboxilato apresentou importante atividade com uma CIM de $5 \mu \mathrm{g} / \mathrm{ml}$ para C. sphaerospermun.

Rüegg et al. (2006), verificaram que o ácido 3-farnesil-2-hidroxibenzóico, obtido a partir das folhas de $P$. multiplinervium, apresentou CIM de 37,5 $\mu \mathrm{g} / \mathrm{ml}$ para Helicobacter pylori, e CIM de 2,5 a $5 \mu \mathrm{g} /$ $\mathrm{ml}$ para Staphylococcus aureus, Escherichia coli, Klebsiella pneumoniae, Mycobacterium smegmatis, Pseudomonas aeruginosa e Candida albicans.

Em nossos estudos anteriores foi demonstrada a atividade antiinflamatória tópica do extrato hidroetanólico das folhas da $P$. ovatum e das amidas piperovatina e piperlonguminina isoladas das folhas dessa espécie (Silva et al., 2008). Além disso, o extrato hidroetanólico, algumas frações desse extrato e as substâncias puras, piperovatina e piperlonguminina, apresentaram importante atividade frente às formas promastigotas e amastigotas axênicas de Leishmania amazonensis (Silva et al., 2009a). Posteriormente, outro estudo demonstrou a atividade antifúngica dos extratos hidroetanólicos das folhas, caules e raízes da $P$. ovatum e das amidas piperovatina e piperlonguminina para cepas padrão e isolados clínicos de Bacillus subtilis e Candida tropicalis. O óleo essencial das folhas da $P$. ovatum também apresentou atividade antifúngica para $C$. tropicalis. Além disso, as amidas apresentaram baixa toxicidade para células Vero e macrófagos (Silva et al., 2009b).

Devido à importância das atividades biológicas apresentadas pela espécie vegetal Piper ovatum e considerando a escassez de estudos relacionados a essa espécie, no presente trabalho foram descritas as características morfo-anatômicas que contribuem com a morfodiagnose de espécies de Piper utilizadas como fitoterápicos. Além disso, também foi estabelecido o perfil cromatográfico do extrato hidroetanólico obtido das folhas de $P$. ovatum com o objetivo de contribuir com o controle de qualidade das espécies de Piper.

\section{MATERIAL E MÉTODO}

O material botânico utilizado foram os fragmentos do primeiro e terceiro entrenós caulinares, das folhas e das raízes adventícias de $P$. ovatum, coletados de espécimes situados em remanescentes florestais do município de Monte Formoso - MG (1651'45.6”S 4115'03.6”W), Brasil em janeiro de 2006. Exsicatas das espécies estudadas encontram-se depositadas como documento taxonômico e material testemunho no Herbário da Universidade Estadual de Maringá, Paraná, sob registro HUEM 10621 e HUEM 11609, a espécie foi identificada pela Dra. Elsie Franklin Guimarães, pesquisadora do Jardim Botânico do Rio de Janeiro - RJ, Brasil.

Os estudos anatômicos foram realizados em material fresco e fixado, para fixação foi utilizado FAA 50 e conservados em etanol $70 \%$ (Jesen, 1962). Secções transversais e paradérmicas dos fragmentos foram realizados á mão livre, com auxílio de lâminas de barbear e corados com Azul de Astra e Safranina a $1 \%$, procedendo-se a montagem de lâminas semi-permanentes em gelatina glicerinada (Gerlach, 1969). As fotomicrografias foram obtidas por sistema de captura de imagens e as escalas referentes às ilustrações foram obtidas utilizando- 
se lâmina micrométrica nas mesmas condições ópticas utilizadas para cada caso. A caracterização morfológica da superfície foliar foi complementada com análise em microscopia eletrônica de varredura (MEV), segundo a técnica de Robbards (1978) e a descrição das características da superfície foliar, mais especificamente com a relação aos aspectos da cuticularização, foi realizada de acordo com a padronização sugerida por Barthlott et al. (1998).

Com a finalidade de comparar dados para a diagnose e identificação da droga vegetal, foram montadas lâminas semi-permanentes com o pó das folhas, caule e raiz, após secagem, moagem e tamisação, resultando em uma mistura homogênea de tenuidade 20 mesh. Os pós obtidos foram clarificados com solução de hipoclorito de sódio $33 \%$, durante 3 minutos, lavado sucessivas vezes com água destilada e montados para observação entre lâmina e lamínula em gelatina glicerinada (Albiero et al., 2001).

\section{Instrumentação e condições cromatográ- ficas}

As análises por cromatografia líquida de alta eficiência foram realizadas em cromatógrafo GILSON modelo 321, equipado com bomba quaternária Gilson 321, injetor automático Gilson 234 com loop de $20 \mu \mathrm{L}$, sistema de desgaseificação de solvente Gilson Degasser 865, detector de comprimento de onda variável Gilson UV 152, forno Gilson 831 e software BOWTER para controle. Nas análises cromatográficas foi utilizada uma coluna de fase reversa Metasil ODS $(5 \mu \mathrm{m}, 150,0 \times 4,6$ $\mathrm{mm}$ ), mantida em forno à temperatura de $30^{\circ} \mathrm{C}$. A eluição foi realizada usando um sistema gradiente de acetonitrila-água $(\mathrm{v} / \mathrm{v})$, iniciando com $0 \%$ de acetonitrila para $60 \%$ em 5 minutos e acetonitrilaágua $60-40(\mathrm{v} / \mathrm{v})$ por 5 minutos, contendo $1 \%$ de ácido acético, fluxo de $1 \mathrm{~mL} / \mathrm{min}$ e a detecção das substâncias foi realizada a $280 \mathrm{~nm}$. Todas as análises foram realizadas em triplicata.

\section{Preparo das amostras dos padrões}

As soluções das substâncias padrão, piperovatina e piperlonguminina, na concentração de $1000 \mu \mathrm{g} / \mathrm{mL}$ foram preparadas dissolvendo $1 \mathrm{mg}$ em $1 \mathrm{~mL}$ de metanol, em frasco vial, com auxílio de banho de ultrassom. Em seguida, a amostra foi filtrada através de filtro Millex 0,45 $\mu \mathrm{m}$ (Millipore, São Paulo, Brazil). As amostras foram preparadas em triplicata.

As substâncias piperovatina e piperlonguminina foram isoladas e identificadas conforme descrito em nossos estudos anteriores (Silva et al., 2008; Silva et al., 2009).

\section{Preparo das amostras do extrato}

As folhas de $P$. ovatum foram secas em estufa de ar circulante, à $36^{\circ} \mathrm{C}$, durante $80 \mathrm{~h}$ e moídas em moinho de martelos (10,0 g). O extrato foi preparado por maceração em solução hidroetanólica $(90: 10 \mathrm{v} / \mathrm{v})$ à temperatura ambiente até completo esgotamento. $\mathrm{O}$ extrato foi filtrado, concentrado em rotaevaporador, à temperatura de $37^{\circ} \mathrm{C}$ e liofilizado $(2,3 \mathrm{~g})$. As soluções do extrato das folhas de $P$. ovatum na concentração de $4000 \mu \mathrm{g} / \mathrm{mL}$ foram preparadas dissolvendo $4 \mathrm{mg}$ do extrato em $1 \mathrm{~mL}$ de metanol, em frasco vial, com auxílio de banho de ultrassom. Em seguida, a amostra foi filtrada através de filtro Millex 0,45 $\mu \mathrm{m}$ (Millipore). As amostras do extrato das folhas foram preparadas em triplicata

\section{RESULTADOS E DISCUSSÃO}

A espécie vegetal Piper ovatum é um arbusto de aproximadamente $2 \mathrm{~m}$ de altura, bastante ramificado. As folhas são oval-elípticas, medindo de $11-14 \mathrm{~cm}$ de comprimento por $3-7 \mathrm{~cm}$ de largura, de cor verde-acinzentada com textura glabra. As flores são do tipo espiga de cor creme-esverdeadas e localizam-se opostas as folhas.

O sistema radical apresenta-se muito ramificado não havendo distinção de uma raiz principal. As raízes apresentam crescimento secundário, a epiderme é uniestratificada com divisões anticlinais e apresenta células suberificadas. No córtex persistente mais externamente foi observado anel contínuo de esclerênquima constituído de 2 a 3 estratos de células. Abaixo das camadas de células do córtex ocorrem idioblastos cristalíferos, contendo cristais prismáticos de oxalato de cálcio e células parenquimáticas contendo grãos de amido e endoderme com estrias de Caspary. $O$ xilema apresenta-se bem desenvolvido e poucos elementos de protoxilema foram evidenciados (Figura 1-2). Neste estudo, foi observado um estelo limitado externamente por anel esclerenquimático unisseriado e a presença de pêlos absorventes nas raízes mais jovens, de acordo com as características descritas anteriormente por Metcalfe \& Chalk (1957) para a espécie $P$. betle.

Sistema radicular semelhante ao de $P$. ovatum foi descrito por Albiero et al. (2005a; 2006) para as espécies $P$. crassinervium e $P$. hispidum, destacando-se nessas espécies a presença de idioblastos oleíferos e a presença de esclereídes em grupos de 1 a 3 células no parênquima cortical externo.

O caule é circular em secção transversal e apresenta estrutura primária, constituído de epiderme unisseriada, com células cubóides (Figura 3). No córtex parenquimático ocorrem faixas descontínuas de colênquima angular, que gradualmente sofre

Rev. Bras. PI. Med., Campinas, v.17, n.2, p.324-330, 2015. 
esclerificação centrífuga (Figura 3). Idioblastos contendo drusas podem ser observados em região mais interna do córtex. O tecido vascular está organizado em círculos descontínuos de feixes colaterais delimitados externamente por endoderme com estrias de Caspary e periciclo uniestratificado, e internamente por bainha perimedular esclerificada. O parênquima medular é homogêneo e constituído de células arredondadas, onde se encontram os feixes colaterais dispostos em círculos (Figura 4).

A estrutura caulinar em $P$. ovatum assemelha-se as espécies Piper já estudadas, entretanto para $P$. crassinervium, conforme descrição de Albiero e colaboradores (Albiero et al., 2005b), o colênquima angular é contínuo.

A distribuição dos feixes vasculares medulares observada no presente estudo é uma característica marcante das espécies de Piperaceae. Alguns autores como Hutchinson (1973)e Cronquist (1981) enfatizaram que a distribuição dos feixes vasculares nas espécies da família Piperaceae é similar a das monocotiledôneas, outros estudos

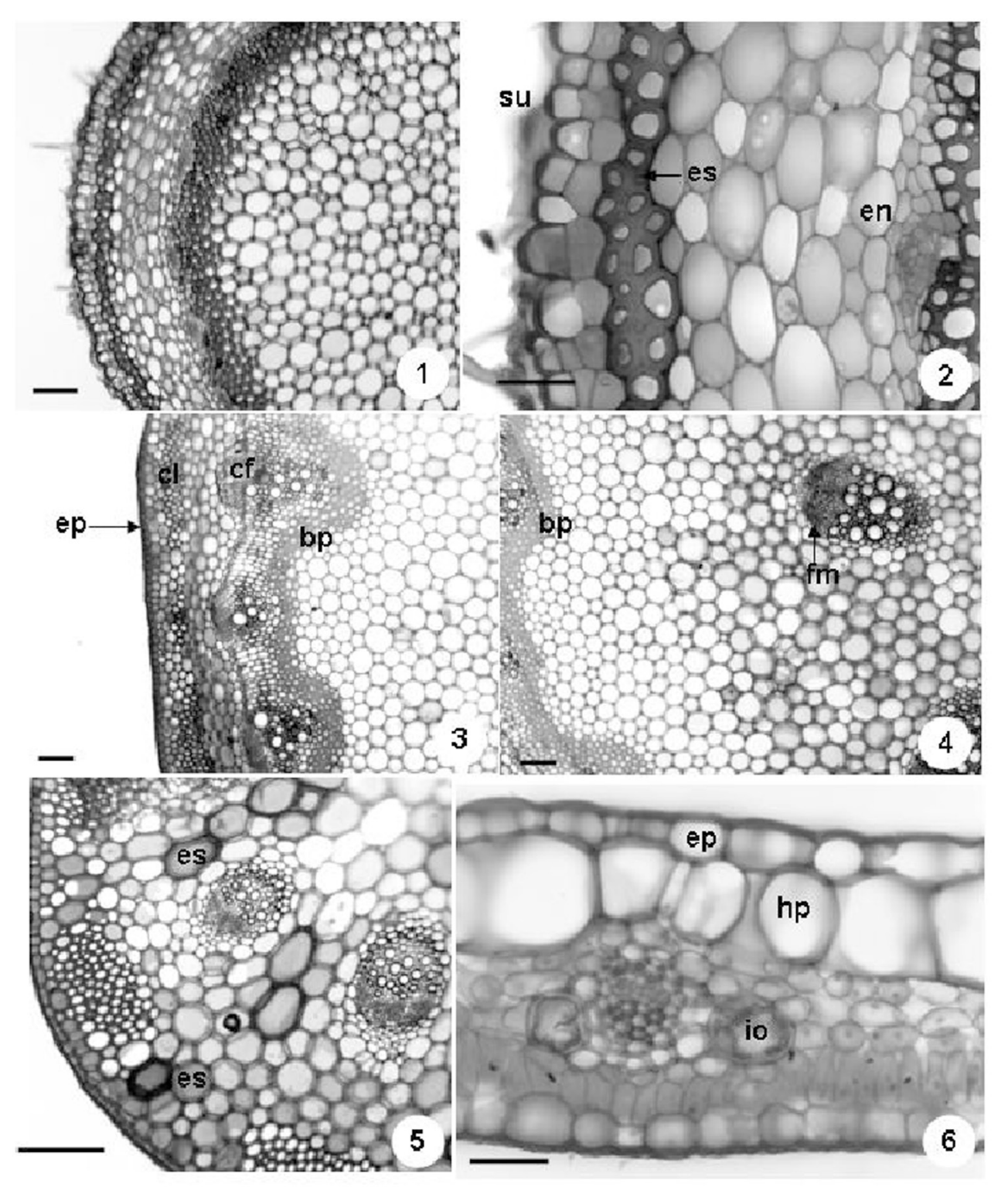

FIGURAS 1-6. Piper ovatum. 1-2: Secções transversais da raiz 1: Aspecto geral da raiz em estrutura secundária

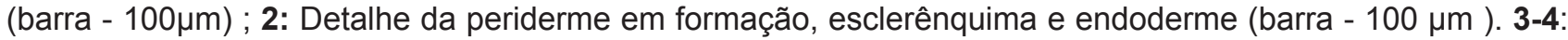
Secções transversais do caule. 3: Caule em início de crescimento secundário, detalhe a bainha perimedular (barra - $100 \mu \mathrm{m})$ 4: Detalhe feixe medular. (barra - $100 \mu \mathrm{m}$ ) 5: Pecíolo em secção transversal, em detalhe os esclereídes (barra - $100 \mu \mathrm{m}$ ). 6: Secção transversal do limbo, em detalhe a hipoderme e idioblastos oleíferos (barra - $50 \mu \mathrm{m}$ ) (bp - bainha perimedular; cl - colenquima; cf - câmbio fascicular; su - súber; en - endoderme; ep-epiderme; ec-esclerênquima; es - esclereídes; fm - feixe medular; hp - hipoderme; io - idioblasto oleífero). 

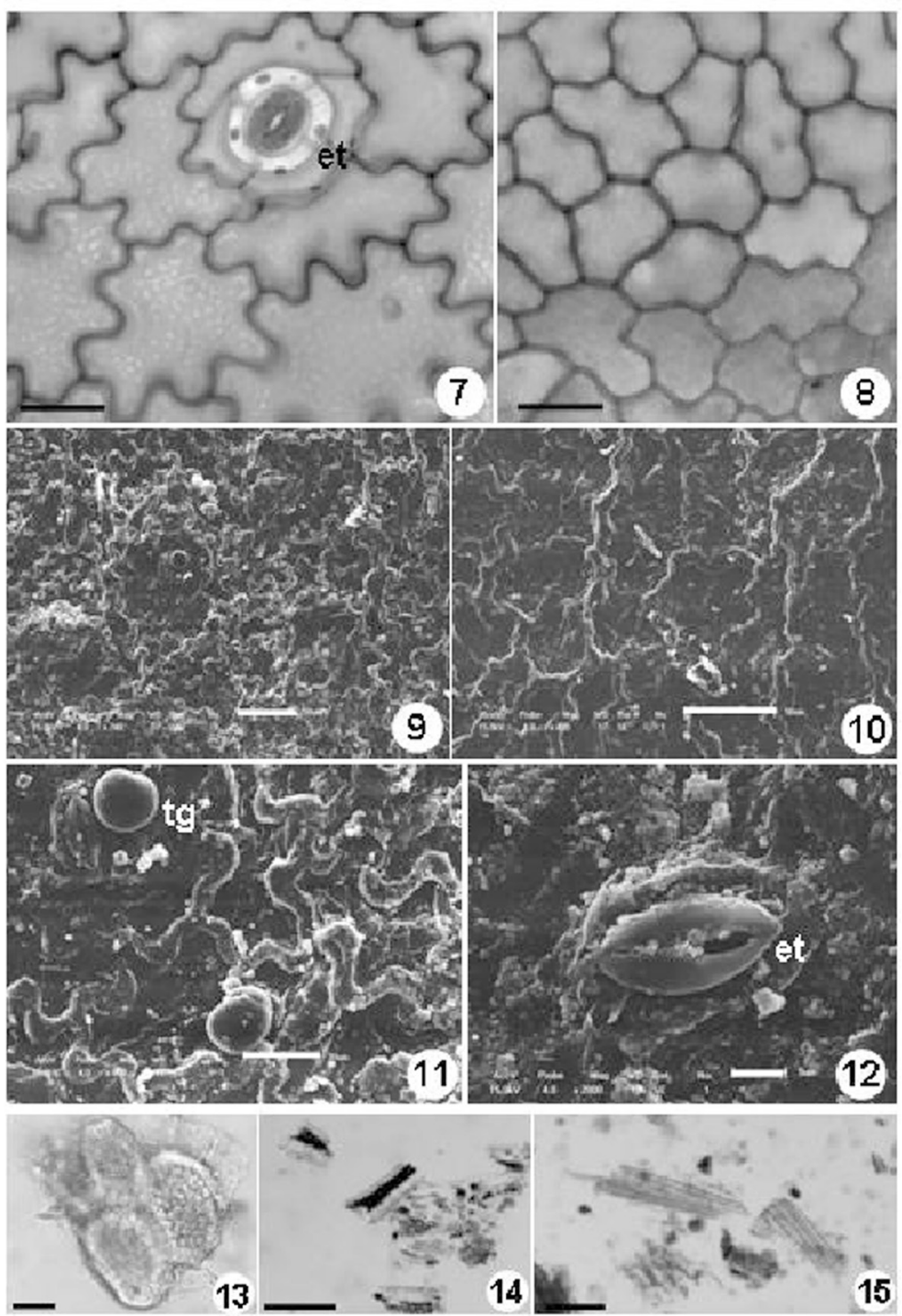

FIGURAS 7-12. Piper ovatum. 7-8: Secções paradérmicas da folha. 7: Detalhe do complexo estomático na

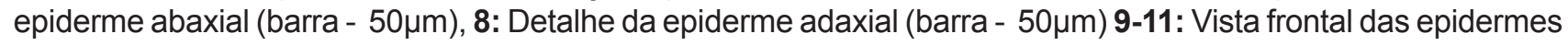
em MEV. 9: Aspecto geral da epiderme abaxial. 10: aspecto geral epiderme adaxial; 11: detalhe da epiderme abaxial evidenciando tricoma grandular. 12: detalhe do estômato. 13-15: Microscopia do pó. 13: Detalhes dos esclereídes do pecíolo (barra - $50 \mu \mathrm{m}$ ); 14: fragmentos do mesófilo mostrando hipoderme (barra - $100 \mu \mathrm{m}$ ); 15: Fragmentos das fibras esclerenquimáticas do caule (bar - $100 \mu \mathrm{m})$. (tg - tricoma glandular; et - estômato)

mais recentes também discutem essa característica (Pessini et al., 2003; Albiero et al., 2005a,b).

A região mediana do pecíolo das folhas é reta e em secção transversal é cilíndrica. A epiderme é unisseriada e no parênquima fundamental ocorrem oito feixes vasculares colaterais de tamanho uniforme, dispostos em círculo, opostos as faixas descontínuas de colênquima angular subepidérmico. Entre os feixes vasculares ocorrem esclereídes isolados ou em grupos de 3 a 4 elementos (Figura 5). A nervura central tem organização semelhante a dos tecidos do pecíolo, exceto pela presença dos esclereídes e pela diminuição do número de feixes vasculares que passam de oito na região basal para apenas um no ápice.

$\mathrm{Na}$ folha hipoestomática, o mesófilo é dorsiventral, com parênquima paliçádico uniestratificado e parênquima lacunoso constituído por duas a três camadas de células isodiamétricas. Abaixo da epiderme abaxial foi observada uma camada de células grandes desprovida de cloroplastos, que na região da nervura central se torna constituída por duas ou três camadas de células, tal camada constitui uma hipoderme (Figura $6)$.

A presença da hipoderme foi relatada por Yuncker (1972) em Piper spp., Vianna \& Akisue (1997) em Piper aduncum, Nascimento \& Vilhena- 


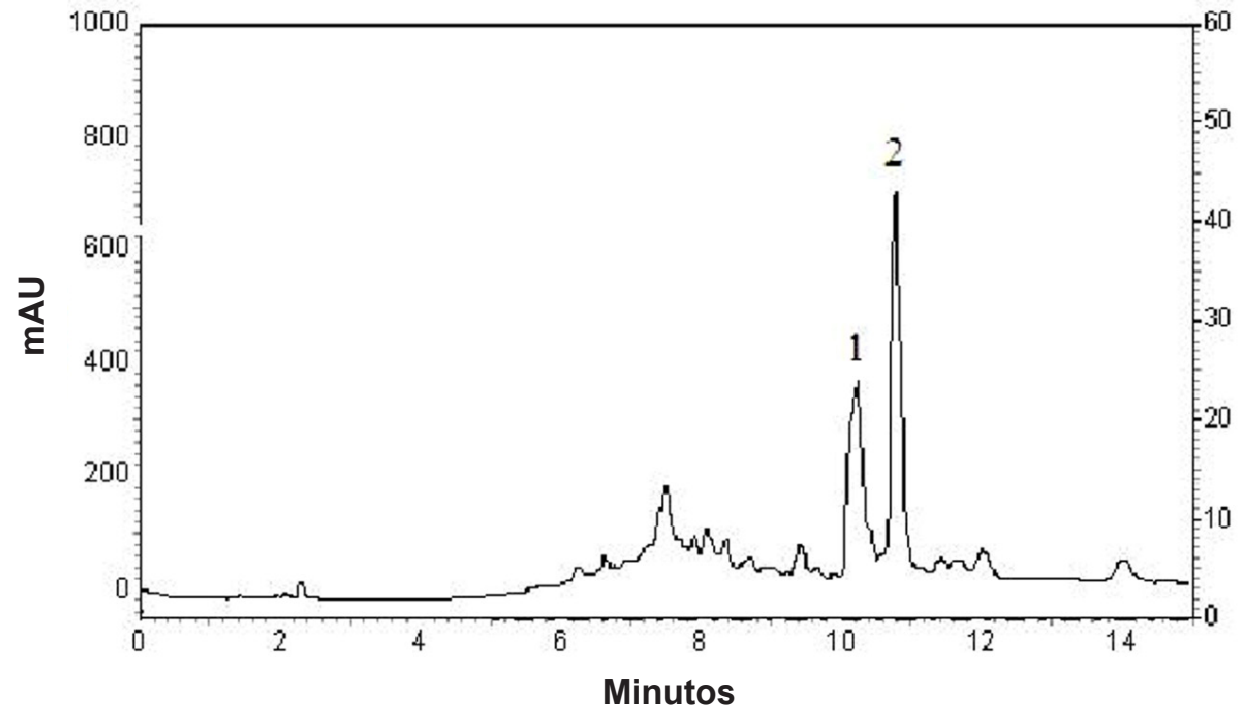

FIGURA 16. Cromatograma do extrato das folhas de $P$. ovatum, (1) piperovatina e (2) piperlonguminina. Condições cromatográficas: coluna Metasil ODS; fase móvel: acetonitrila/água (v/v), iniciando com acetonitrila $0 \%$ a $60 \%$ por 5 minutos; em seguida acetonitrila-água $60-40$ por 15 minutos com $1 \%$ de ácido acético; fluxo: 1,0 mL/min; temperatura: $30^{\circ} \mathrm{C}$; detecção: $280 \mathrm{~nm}$.

Potiguara (1999) em P. hispidinervium e por Albiero et al. (2006) em P. hispidum.

Em secção transversal das folhas, a epiderme do limbo foliar é uniestratificada nas faces abaxial e adaxial, sendo constituída por células cúbicas a retangulares recobertas por cutícula (Figura 6). Idioblastos contendo material lipofílico foram observados no parênquima clorofiliano de $P$. ovatum, mais especificamente ladeando os feixes vasculares (Figura 6). Essas células secretoras de conteúdo oleífero ou mucilaginoso foram relatadas por Metcalfe \& Chalk (1957) no caule e nas folhas de todos os gêneros de Piperaceae, com exceção de Symbrio. Outras inclusões celulares relatadas para as espécies da família Piperaceae, como por exemplo, cristais de oxalato de cálcio, não foram observados nas folhas de $P$. ovatum.

Em secção paradérmica das folhas, na face abaxial os estômatos são do tipo anomocítico (Figuras 7-12) e na face adaxial as células da epiderme apresentam contorno sinuoso e não foram observados estômatos e tricomas (Figura 8). Análises por MEV mostraram a presença de tricomas glandulares esparsos constituídos de pedúnculo unicelular e porção secretora globóide igualmente unicelular, recoberto pela cutícula na epiderme abaxial (Figura 11). Além disso, também foi observada por MEV a presença de uma cutícula espessa e que origina crostas no limite entre uma célula e outra (Figuras 9-10), em ambas as superfícies foliares.

Estudos anteriores descreveram a presença de tricomas tectores e gladulares com célula apical em forma de saco, em ambas as faces da epiderme das folhas de $P$. hispidinervium (Nascimento \& Vilhena-Potiguara 1999). Também, Pessini et al. (2003) descreveram a ocorrência de tricomas glandulares capitados em ambas as faces, raros tricomas tectores pluricelulares e unisseriados e de extremidade afilada sobre as nervuras nas folhas de $P$. regnellii var. pallescens. Em estudos com $P$. crassinervium e $P$. hispidum, Albiero et al. (2005a, 2006) descreveram a presença de tricomas glandulares com porção secretora curvada sobre a epiderme e três tipos de tricomas tectores, respectivamente. Dessa forma, pode-se admitir que a presença de tricomas glandulares e também de tectores em Piper é uma característica importante para a diagnose das espécies.

No pó de $P$. ovatum foram observados elementos marcantes que podem auxiliar na identificação e nas análises de avaliação de qualidade da droga vegetal para comercialização, tais como, fragmentos do limbo, nos quais puderam ser evidenciados a hipoderme e os idioblastos oleíferos (Figura 14), fragmentos de fibras esclerenquimáticas do caule (Figura 15), além dos esclereídes isolados ou em grupos observadas no parênquima fundamental do pecíolo (Figura 13).

Nas análises do perfil cromatográfico do extrato hidroetanólico das folhas de $P$. ovatum foram detectadas como substâncias majoritárias as amidas piperovatina (1) e piperlonguminina (2) nos tempos de retenção 10,25 e 10,81 min., respectivamente (Figura 16).

A descrição das características morfológicas e anatômicas das raízes, caules, pecíolo, folhas e pó de $P$. ovatum e a determinação do perfil 
cromatográfico do extrato das folhas realizadas no presente estudo contribui para a morfodiagnose e controle de qualidade de espécies do gênero Piper utilizadas como plantas medicinais.

\section{AGRADECIMENTOS}

Agradecemos o Conselho Nacional de Desenvolvimento Científico e Tecnológico (CNPq), a Capacitação de Aperfeiçoamento de Pessoal de Nível Superior (CAPES) e o Programa de Pós-graduação em Ciências Farmacêuticas da Universidade Estadual de Maringá pelo suporte financeiro.

\section{REFERÊNCIAS}

ALBIERO, A.L.M; PAOLI, A.A.S.; SOUZA, L.A.; MOURÃO, K.S. Morphology and anatomy of vegetative organs of Piper crassinervium H.B. K. (Piperaceae). Acta Botânica Brasílica, v.19, p.305-312, 2005a.

ALBIERO, A.L.M.; SOUZA, L.A.; MOURÃO, K.S.; ALMEIDA, O.J.G.; LOPES, A.L. Morfoanatomia do caule e da folha de Piper gaudichaudianum Kuntze (Piperaceae). Acta Farmacêutica Bonaerense, v.24, p.550-554, 2005b.

ALBIERO, A.L.M.; PAOLI, A.A.S.; SOUZA, L.A.; MOURÃO, K.S. Morfoanatomia dos órgãos vegetativos de Piper hispidum Sw. (Piperaceae). Brazilian Journal of Pharmacognosy, v.16, p.379-391, 2006.

BARTHLOTT, W.; NEINHUIS, C.; CUTLER, D.; DITSCH, F.; MENSEL, I.; THEISEN, I.; WILHELM, H. Classification and terminology of plant epicuticular waxes. Botanical Journal of the Linnean Society, v.126, p.237-260, 1998.

GERLACH, G. Botanische microtechnik. Eine einfuhrung. George Thiem, Stuttgard, 1969.

GRAYER, R.J.; HARBORNE, J.B. A survey of antifungal compounds from higher plants. Phytochemistry, v.37, n.1, p.19-42, 1994.

LÓPEZ, A.; MING, D.S.; TOWERS, G.H.N. Antifungal activity of benzoic acid derivatives from Piper lanceaefolium. Journal of Natural Products, v. 65, p.62-64, 2002.

MARTINS, R.C.; LAGO, J.H.; ALBUQUERQUE, S.; KATO, M.J. Trypanocidal tetrahydrofuran lignans from inflorescences of Piper solmsianun. Phytochemistry, v.64, p.667-670, 2003.

METCALFE, C.R.; CHALK, L. Anatomy of the dicotyledons - leaves, stem and wood in relation to taxonomy with notes on economic uses. Clarendon Press, Oxford, 1957.

METCALFE, C.R.; CHALK, L. Anatomy of the dycotiledons. Claredom Press, Oxford, 1972.
NASCIMENTO, M.E.; VILHENA-POTIGUARA, R.C. Bol Mus Emílio Goeldi série Botânica, v.15, p.39-104, 1999.

PARK, S.B.; LEE, S.E.; SHIN, S.C.; PARK, J.D.; AHN, Y.J. Larvicidal activity of isobutylamides identified in Piper nigrum fruits against three mosquito species. Journal of Agricultural and Food Chemistry, v.50, p. 866-1870, 2002.

PESSINI, G.L.; HOLETZ, F.B.; SANCHES, N.R.; CORTEZ, D.A.G.; DIAS-FILHO, B.P.; NAKAMURA, C.V. Atividade antileishmania do extrato hidroalcoólico e de frações obtidas de folhas de Piper regnellii (Miq.) C. DC. var. pallescens (C. DC.).Yunck. Revista Brasileira de Farmacognosia, v.13, Supl 1, p.21-24, 2003.

RÜEGG, T.; CALDERON, A.I.; QUEIROZ, E.F.; SOLIS, P.N.; MARSTON, A.; RIVAS, F.; ORTEGA-BARRÍA, E.; HOSTTETMAN, K.; GUPTA, M.P. 3-Farnesyl-2hydroxybenzoic acid is a new anti-Helicobacter pylori compound from Piper multiplinervium. Journal of Ehtnopharmacology, v.103, p.461-467, 2006.

SALAZAR, K.J.M.; PAREDES, G.E.D.; LUNCOR, L.R.; YOUNG, M.C.M.; KATO, M.J. Chromones of polyketide origin from Peperomia villipetiola. Phytochemistry, v.66, p.573-579, 2005.

SILVA, D.R.; BARONI, S.; SVIDZINSKI, A.E.; BERSANIAMADO, C.A.; CORTEZ, D.A.G. Anti-inflammatory activity of the extract, fractions and amides from the leaves of Piper ovatum Vahl (Piperaceae). Journal of Ethnopharmacology, v.116, n.3 p.569-573, 2008.

SILVA, D.R.; NAKAMURA, C.V.; DIAS-FILHO, B.P.; UEDA-NAKAMURA, T.; CORTEZ, D.A.G.. In vitro Antileishmanial Activity of Hydroalcoholic Extract, Fractions, and Compounds Isolated from Leaves of Piper ovatum Vahl against Leishmania amazonensis. Acta Protozoologica, v.48, p.73-81, 2009a.

SILVA, D.R.; ENDO, E.H.; DIAS-FILHO, B.P.; NAKAMURA, C.V.; SVIDZINSKI, A.E.; SOUZA, A.; YOUNG, M.C.M.; UEDA-NAKAMURA, T.; CORTEZ, D.A;G; Chemical Composition and Antimicrobial Properties of Piper ovatum Vahl. Molecules, v.14, p.1171-1182, 2009b.

SOLEREDER, M. Sistematic anatomy of the Dicotyledons. Clarendon Press, Oxford, 1908.

SOUZA, V.C.; LORENZI, H. Botânica sistemática Guia ilustrado para identificação de famílias de angiospermas da flora brasileira, baseado em APG II. Instituto Plantarum de Estudos da Flora, Nova Odessa, 2005.

VIANA, W.O.; AKISUE, G. Caracterização morfológica de Piper aduncum. Lecta, v.15, p. 11-62, 1997.

YUNCKER, T.G. The Piperaceae of Brazil - I. Piper group I, II, III, IV. Hoehnea, v.2 p.19-366, 1972.

ZACCHINO, S.; RODRÍGUES, G.; PEZZENATI, G.; ORELLANA, G. In vitro evaluation of antifungal properties of 8.O.4'-neolignans. Journal of Natural Products, v.60, p.659-662,1997. 